\title{
Achieving universal health coverage in sub-Saharan Africa: the role of leadership development
}

\author{
Janet Michel', M Ishaaq Datay', Thabang J Motsohi ${ }^{3}$, Till Bärnighausen ${ }^{4}$, Fabrizio Tediosi', Di Mclntyre ${ }^{5}$, Marcel Tanner ${ }^{1}$ \\ , David Evans ${ }^{6}$ \\ 1 Swiss Tropical and Public Health Institute (Swiss TPH), Basel, Switzerland; University of Basel, Basel, Switzerland, 2 Primary Health Care Directorate, \\ University of Cape Town, Cape Town, South Africa, ${ }^{3}$ Fit for Purpose, Johannesburg, South Africa, ${ }^{4}$ Institute of Public Health, University of Heidelberg, \\ Heidelberg, Germany; Harvard T. H. Chan School of Public Health, Boston, Massachusetts, USA, ${ }^{5}$ Health Economics Unit, University of Cape Town, \\ Cape Town, South Africa, ${ }^{6}$ World Bank Health Economist, Geneva, Switzerland \\ Keywords: leadership development, role of context, uhc, sub-saharan africa \\ https://doi.org/10.29392/001c.12855
}

\section{Journal of Global Health Reports}

Vol. 4, 2020

\begin{abstract}
Countries world-wide are striving towards Universal Health Coverage (UHC). Financial resources are extremely limited in developing countries and many developing countries are in the midst of multiple interconnected social, economic, epidemiologic, demographic, technological, institutional, environmental and political transitions. According to the World Health Organization (WHO), accelerating progress towards UHC in Africa will require strong leadership. At the recent Global Conference on Primary Health Care (PHC), the Astana Declaration, the world recommitted to comprehensive Primary Health Care as a keystone of Universal Health Coverage. There is evidence that PHC works. Countries that followed the Alma Ata PHC principles have demonstrated population health outcomes and reduced inequalities at low costs as seen in Chile, Cuba, Ethiopia and Rwanda. What seems to be missing is leadership to apply and uphold these PHC principles. There is consensus that if Astana is to be realized, strong political, economic, education, health, science, institutional, and community leaders are needed to make PHC work this time around. Governments and leaders in Africa have been conveying a constant message, that those leading and managing health systems are not sufficiently prepared to succeed in leadership roles they now occupy. Africa has had different leaders with the same results for decades. Leadership development efforts made to date seem not to be producing desired results. Students taken out of Africa to be trained in leadership at western universities, seem to go back home and carry on as usual. Many students have been taken to the West for education, developed great visions and ideas of how they can transfer knowledge learnt, got home and got swallowed by the system. Pumping more money into a health system with no leadership development will not help us achieve 'Health for All' in sub-Saharan Africa. How can accountable leadership with a sense of consciousness for social justice be developed successfully in these contexts? If leadership is key for Universal Health Coverage to be achieved in sub-Saharan Africa, is it not high time attention is paid to leadership development approaches.
\end{abstract}

At the recent Global Conference on Primary Health Care (PHC), the Astana Declaration, the world recommitted to comprehensive Primary Health Care as a keystone of Universal Health Coverage. ${ }^{1}$ The definition of Universal Health Coverage (UHC) embodies three objectives namely: i) equity in access to health services-everyone who needs services should get them, not only those who can pay for them; ii) the quality of health services should be good enough to improve the health of those receiving services; and iii) people should be protected against financial risk, meaning ensuring that the cost of using services do not put people at risk of financial harm. 1,2

Since the 1978 Alma- Ata agreement on Health for All, the birth of the idea of PHC, significant progress has been witnessed with a $50 \%$ reduction in mortality of children under five, improved life expectancy and decreased mortali- ty globally. ${ }^{3}$ Yet today far too many preventable deaths still occur. ${ }^{3}$ At least half of the world's population still do not have full coverage of essential health services. About 100 million people are still being pushed into extreme poverty because they have to pay for health care out-of-pocket. Over 800 million people spent at least $10 \%$ of their household budgets to pay for health care. One billion people live beyond the reach of a modern health system and do not benefit from public health efforts others take for granted. ${ }^{3}$

\section{PHC STATUS IN AFRICA}

African countries have continued to occupy the lowest rung of the ladder in the area of primary health care delivery. In spite of the various global efforts, including funds and technical support, healthcare in many African PHC systems 
have remained deplorable, unattractive, and irresponsive to peoples' needs. ${ }^{4-6}$ PHC failed the first-time round in South Africa, because insufficient attention was given to its implementation, resulting in a neglect of taking comprehensive services to communities, disease prevention, health promotion and community participation. Some of the major challenges facing PHC today include inadequate political, financial, human and material commitments, suboptimal use of available resources, challenges in changing management techniques including decentralization and ensuring effective community participation and intersectoral collaboration. ${ }^{7}$ The majority of health systems in Africa are characterized by poor leadership and management and absence of health promoting amenities making PHC in Africa fail. ${ }^{4}$ Meaningful community participation in PHC has not been achieved to date. ${ }^{8}$

\section{SOME SPECIFICS MISSING IN THE ASTANA DECLARATION}

The Astana declaration reconfirms the solidarity of commitment to the right of 'Health for All' enshrined in AlmaAta declaration, specific actions needed to make this vision a reality are as absent as they were in $1978 .^{9}$ This leaves room for many challenges including a dangerous tilt towards personal health care at the expense of population health and a hands off approach to governance allowing commercialization of health care to flourish. ${ }^{9}$ There is also the danger of a shift towards vertical approaches and an entrenchment of selective primary health care which caused a failure in realisation of the Alma Ata vision. ${ }^{3}$

\section{UHC FINANCING}

Financial resources are extremely limited in developing countries and resources are often poorly distributed among regions urban and rural. Although member states of the African Union agreed to allocate at least $15 \%$ of their national budgets to health (2001 Abuja declaration), only five countries in the region have been able to do so including South Africa. Evidence shows that in many developing countries, resources available for health are less than required to deliver the national minimum health care package, leaving households to carry a heavy out-of-pocket expenditure. ${ }^{4,10}$ Community health funds have been proven to be ineffective, donor funding not sustainable and general tax as the most reliable mechanism to finance health. How can this be achieved in the current context of inadequate economic growth, conflicts, migration, unemployment, poor management of public services and not to mention corruption? ${ }^{4,11,12}$

\section{MULTIPLE EPIDEMICS AT THE BACKDROP OF RESOURCE CHALLENGES}

Noteworthy, many developing countries in sub-Saharan Africa are in the midst of multiple interconnected social, economic, epidemiologic, demographic, technological, institutional, environmental and political transitions. Multiple epidemics are being experienced simultaneously, HIV, TB, Violence, Maternal and Child mortality, NCDs and Ebo- la to mention but a few. ${ }^{13}$ These changes impact on health and well-being, as well as the capacity of health systems to respond. Different countries have adopted different paths to UHC. ${ }^{14}$ In many African countries including Algeria, Cameroon, Central Africa Republic, Democratic Republic of Congo, Kenya, Niger, Nigeria, Senegal, Uganda and South Africa, weak health systems, poor preparedness for health emergencies, poor quality of care and an overall inadequacy of drug supply have been reported as challenges. ${ }^{15}$ Capacity in planning, management and human resources development remains weak and gaps in human resources for health numbers, skill mix and distribution pose a challenge for effective service delivery. ${ }^{9}$ Even in parts of South Africa, like the Western Cape, where when compared with the rest of Africa, better infrastructure exists, greater efforts are required to address the upstream determinants of health which continue be major challenges. ${ }^{16}$

\section{LEADERSHIP GAPS IN ALL SPHERES OF THE SOCIETY - POLITICAL, ECONOMIC, EDUCATIONAL, HEALTH, AND AGRICULTURE}

According to the World Health Organization (2000) report, poor organizational structure, bad leadership, insufficient funding, and corruption are among the problems that affect the delivery of health care. ${ }^{4,17}$ The effects of poor leadership and inefficient health management greatly affect the manner in which residents have access to the health care they need. ${ }^{4,17}$ This problem is more peculiar in developing African countries. ${ }^{4,6,17}$ Healthcare leadership means the ability of the managers of the health-care system to look ahead, identify problems, propose solutions, and plan strategies to overcome them. ${ }^{4,17}$ Governments and leaders in Africa have been conveying a constant message, that those leading and managing health systems are not sufficiently prepared to succeed in leadership roles they now occupy. 4,18 It is the interplay of power and character that for many has proved to be the ultimate test of capability and effectiveness in the crucible of leadership-here many fail the test. $^{19}$

\section{"The most challenging test of my administration as president was the temptation to abuse power." Nelson Mandela. ${ }^{19}$}

\section{EVIDENCE SHOWS THAT PHC WORKS}

There is evidence that PHC works. Countries that followed the Alma Ata PHC principles have demonstrated population health outcomes and reduced inequalities at low costs as seen in Chile, Cuba, Ethiopia, Nepal, Rwanda and Sri Lanka. ${ }^{9}$ What seems to be missing is leadership to apply and uphold the principles. Africa has had different leaders with the same results for decades. ${ }^{5,18,20}$ For the above mentioned challenges to be addressed, the cultivation of leaders with exceptional character, skill and a sense of accountability to communities served is paramount. ${ }^{9,18}$ There is a need to strengthen leadership and governance in the health system if UHC policy implementation is to succeed. ${ }^{21}$ Africa needs leadership development systems that produces leaders that are willing to serve and not be served, where occupying a leadership position does not make leaders superior 
and unaccountable to the people they lead. $5,18,22$

\section{LEADERSHIP DEVELOPMENT EFFORTS TO DATE}

Context in leadership has been ignored, may be because partly context is difficult to quantify. ${ }^{23}$ Context matters and it matters a lot.6,23-25 The role of contextual intelligence cannot be overemphasized.6,19 Leadership development efforts made to date seem not to be producing desired results, 5,18,22 despite leadership being categorised as a critical outcome of training, in for example the health sciences. ${ }^{26}$ Students taken out of Africa to be trained in leadership at western Universities, seem to go back home and carry on as usual. Many students have been taken to the West for education, developed great visions and ideas of how they can transfer knowledge learnt, got home and got swallowed by the system. ${ }^{18}$ Could that be because of context? One is educated in one context (the West) and expected to function in another (Africa)?

\section{COMPLEXITY}

It's the conditions in which people are born, grow up, live and work that determine their health. ${ }^{27}$ For these conditions to be conducive, leadership in all sectors of the society; political, economic, housing, labour, agriculture, education, health etc is needed. ${ }^{5,20}$ In the face of climate change, dwindling resources, multiple epidemics including cancers, we need leaders who can deal with complexities, involving more variables and whose decisions have far reaching implications. The paradox of our time is that best decisions do not require the fastest speed, but more consciousness. ${ }^{19}$ Many leaders seem to lack in systems thinking. Systems are designed to be self-sustaining. An intervention aimed at changing the system fundamentally needs to be carefully selected for its capability to impact the parts of the system that gives the system its life. ${ }^{28}$

\section{LEADERSHIP DEVELOPMENT IS KEY TO ACHIEVING UHC}

If Astana is to be realized, mass quality education and participatory approaches, that empower people and communities to play an active role in shaping policies, and a whole of government approach beyond ministries of health are needed. ${ }^{6,9,19,25}$ For this to happen, leadership across all sectors is needed. Incompetence in leadership in most African countries is not only the problem of people who occupy positions in government, but a reflection of leadership culture. ${ }^{5}$ How can we develop caring leaders with a sense of consciousness for social justice, integrity and character? ${ }^{19}$ Communities and the whole society should have a responsibility to account. Local leadership development and training could be one chance for us to confront dysfunctional systems in context and that could be the impetus for us to resolve issues facing our health systems and society at large. ${ }^{5}$ Adopting UHC is primarily a political rather than technical issue. ${ }^{29}$ The leadership gap seems enormous. Pumping more money into a health system with no leadership development will not help us achieve Health for All in sub-Saharan Africa. According to the WHO 2006 bulletin, poor leadership and inefficient organizational capacity are responsible for ineffective oversight and preponderance of corrupt practices in healthcare delivery. ${ }^{30}$ If Astana is to be realized, strong Political, Economic, Education, Health, Science, Institutional, and Community leaders are needed to make PHC work this time around.6,9,31,32 If leadership is key for Universal Health Coverage to be achieved in sub-Saharan Africa, is it not high time attention is paid to leadership development approaches? How can these leaders be developed successfully? We reckon this as a case for randomized controlled trials (RCTs) ${ }^{32-34}$ in context, to find out what approaches produce the needed results-accountable leadership with a sense of consciousness for social justice.

\section{Box 1. Key messages}

- There is evidence that PHC works. Countries that followed the Alma Ata PHC have demonstrated population health outcomes and reduced inequalities at low costs as seen in Chile, Cuba, Ethiopia, Nepal, Rwanda and Sri Lanka. What seems to be missing is leadership.

- Adopting UHC is primarily a political rather than technical issue. The leadership gap seems enormous. Pumping more money into a health system with no leadership development will not help us achieve Health for All in sub-Saharan Africa. If Astana is to be realized, strong Political, Economic, Education, Health, Science, Institutional, and Community leaders are needed to make PHC work this time around. How can these leaders be developed successfully? We reckon this as a case for randomized controlled trials (RCTs) in context, to find out what approaches produce the needed results-accountable leadership with a sense of consciousness for social justice.

Acknowledgements: I would like to acknowledge my husband, Dr Joerg Michel for encouraging me to put my thoughts on paper and reading the first draft.

\section{Ethics approval: Not applicable}

\section{Funding: None}

Authorship contributions: JM contributed to the initial concept of paper and wrote the first draft. MID, TJM, TB, FT, $\mathrm{DM}, \mathrm{MT}$ and DE commented and contributed to subsequent drafts

Competing Interests: The author completed the Unified Competing Interest form at www.icmje.org/coi_disclosure.pdf (available upon request from the corresponding author), and declare no conflicts of interest. 
Correspondence to:

Janet Michel

PhD student in Epidemiology, Health Systems and Policy

Unit

Swiss TPH, Basel, Switzerland
University of Basel, Switzerland

janetmichel71@gmail.com 


\section{REFERENCES}

1. World Health Organization. What is universal coverage? WHO 2019. http://www.who.int/health fina ncing/universal_coverage_definition/en/. Accessed January 18, 2019.

2. McIntyre D, Doherty J, Ataguba J. Universal Health Coverage Assessment South Africa. South Afr. 2014:16. http://gnhe.org/blog/wp-content/uploads/20 15/05/GNHE-UHC-assessment_South-Africa.pdf. Accessed May 11, 2020.

3. Health Affairs. Implementing The Astana Declaration-What Alma-Ata Taught Us. Health Aff (Millwood). 2018. doi:10.1377/hblog20181024.24072/f ull/

4. Chimezie RO. Failure of Primary Healthcare Delivery in Africa 2015; 2:8. http://www.ijims.com/up loads/89f78190836425dac1f4Rayus26.pdf. Accessed May 11, 2020

5. Afegbua SI, Adejuwon KD. The challenges of leadership and governance in Africa. International Journal of Academic Research in Business and Social Sciences. 2012;2(9):141.

6. Agyepong IA, Sewankambo N, Binagwaho A, et al. The path to longer and healthier lives for all Africans by 2030: The Lancet Commission on the future of health in sub-Saharan Africa. The Lancet. 2017;390(10114):2803-2859. doi:10.1016/s0140-673 $\underline{6(17) 31509-x}$

7. Dookie S, Singh S. Primary health services at district level in South Africa: A critique of the primary health care approach. BMC Fam Pract. 2012;13(1). do i:10.1186/1471-2296-13-67

8. Mulumba M, London L, Nantaba J, Ngwena C. Using Health Committees to Promote Community Participation as a Social Determinant of the Right to Health. Health Hum Rights. 2018;20:11-17.

9. Walraven G. The 2018 Astana Declaration on Primary Health Care, is it useful? Journal of Global Health. 2019;9(1). doi:10.7189/jogh.09.010313

10. World Health Organization. Out-of-pocket payments, user fees and catastrophic expenditure. WHO. 2019. http://www.who.int/health_financing/top ics/financial-protection/out-of-pocket-payments/en/. Accessed June 3, 2019.
11. Mwije S. Corruption and Poor Governance- The Major Causes of Poverty in Many Third world Countries 2013. https://www.academia.edu/1782974 3/Corruption_and Poor_Governance-_The_Major_Cau ses_of Poverty_in_Many_Third_world_Countries. Accessed May 11, 2020.

12. Economic Activities. Economic activities / OSCE 2019. https://www.osce.org/economic-activities. Accessed June 3, 2019.

13. De Cock KM, Simone PM, Davison V, Slutsker L. The New Global Health. Emerg Infect Dis. 2013;19(8):1192-1197. doi:10.3201/eid1908.130121

14. Rao KD, Petrosyan V, Araujo EC, McIntyre D. Progress towards universal health coverage in BRICS: Translating economic growth into better health. Bull World Health Organ. 2014;92(6):429-435. doi:10.247 1/blt.13.127951

15. Africa WHORO for. Health systems in Africa: Community perceptions and perspectives: the report of a multi-country study. World Health Organization Regional Office for Africa. 2012.

16. Western Cape Government. The future of Health Care in Western Cape 2011. https://www.westerncap e.gov.za/other/2011/12/healthcare_2020 - 9 decembe r 2020.pdf. Accessed May 11, 2020.

17. World Health Organization. The world health report 2000 - Health systems: Improving performance. WHO. 2000. https://www.who.int/whr/2 000/en/. Accessed July 31, 2019.

18. Africa doesn't need charity, it needs good leadership. World Econ Forum. https://www.weforu m.org/agenda/2017/05/africa-doesn-t-need-charity-i t-needs-good-leadership/. Accessed January 18, 2019.

19. Motsohi TJ. Fit for Purpose. Wood Rock Publishing; 2018. doi:10.12968/nuwa.2018.9.32

20. A lack of leadership in Africa threatens economic progress. The Independent. 2013. http://www.indepe ndent.co.uk/voices/comment/a-lack-of-leadership-inafrica-threatens-economic-progress-8889974.html. Accessed July 31, 2019.

21. Gilson L. South Africa: Learning sites \& implementation - Nuffield Department of Medicine. 2014. https://www.ndm.ox.ac.uk/lucy-gilson-south-af rica-learning-sites-implementation. Accessed May 23, 2019. 
22. Rispel L. Faultlines in delivering good health care to poor people in South Africa. The Conversation. 2016. http://theconversation.com/faultlines-in-delive ring-good-health-care-to-poor-people-in-south-afric a-48329. Accessed June 12, 2019.

23. Royle C. The Theory Of Contextual Leadership. Won't. 2016. https://medium.com/where-others-won t/weve-been-wrong-about-leadership-this-whole-tim e-b54d8d2b856d. Accessed May 23, 2019.

24. Bressers JTA. From public administration to policy networks: Contextual interaction analysis. Rediscovering Public Law Public Adm Comp Policy Anal Tribute Peter Knoepfel. 2009:123-142.

25. World Health Organization. The World Health Report - primary Health Care (Now More Than Ever). WHO. 2008. https://www.who.int/whr/2008/en/. Accessed July 31, 2019.

26. Chen T-Y. Medical leadership: An important and required competency for medical students. Tzu Chi Med J. 2018;30(2):66. doi:10.4103/tcmj.tcmi_26_18

27. Bloomsbury.com. The Health Gap. Bloomsbury Publ. https://www.bloomsbury.com/uk/the-health-ga p-9781408857991/. Accessed June 2, 2019.

28. Senge PM. The Fifth Discipline: The Art and Practice of the Learning Organization. London: Random House Business Books; 1999.
29. Feigl A, Basu S, McKee M. The political economy of universal health coverage. In: First Global Symposium on Health Systems Research. 2010. Montreux, Switzerland.

30. World Health Organization. Bulletin of the World Health Organization. WHO. 2006. https://www.who.i nt/bulletin/volumes/84/en/. Accessed July 31, 2019.

31. Countries urged to strive for universal access to good quality health to spur economic growth. WHO Regional Office for Africa. 2018. https://afro.who.int/ news/countries-urged-strive-universal-access-good-q uality-health-spur-economic-growth. Accessed June $12,2019$.

32. Curry L, Taylor L, Chen PG-C, Bradley E. Experiences of leadership in health care in subSaharan Africa. Hum Resour Health. 2012;10(1). doi:1 $\underline{0.1186 / 1478-4491-10-33}$

33. Wilson C, Rooshenas L, Paramasivan S, et al. Development of a framework to improve the process of recruitment to randomised controlled trials (RCTs): The SEAR (Screened, Eligible, Approached, Randomised) framework. Trials. 2018;19(1). doi:10.11 86/s13063-017-2413-6

34. White H. An introduction to the use of randomised control trials to evaluate development interventions. Journal of Development Effectiveness. 2013;5(1):30-49. doi:10.1080/19439342.2013.764652 